\title{
Intestinal SALSA/dmbt1 levels are decreased in prematurely born infants
}

\section{Reichhardt, Martin Parnov}

2021-02

Reichhardt , M P , Messing , M , Andersson , S , Kolho , K-L \& Meri , S 2021 , ' Intestinal SALSA/dmbt1 levels are decreased in prematurely born infants ', Scandinavian Journal of Immunology, vol. 93 , no. 2 , 12987 . https://doi.org/10.1111/sji.12987

http://hdl.handle.net/10138/336047

https://doi.org/10.1111/sji.12987

acceptedVersion

Downloaded from Helda, University of Helsinki institutional repository.

This is an electronic reprint of the original article.

This reprint may differ from the original in pagination and typographic detail.

Please cite the original version. 
DR. MARTIN REICHHARDT (Orcid ID : 0000-0001-5345-5103)

Article type : Regular Article

\section{Intestinal SALSA/dmbt1 levels are decreased in prematurely born infants}

Running title: SALSA in premature infants

Martin Parnov Reichhardt ${ }^{1 *}$, Marcel Messing ${ }^{1}$, Sture Andersson², Kaija-Leena Kolho ${ }^{2,3}$, Seppo Meri $^{1}$

${ }^{1}$ Department of Bacteriology and Immunology and Translational Immunology Research Program, University of Helsinki, Helsinki, Finland

${ }^{2}$ Department of Pediatrics and Children's Hospital, University of Helsinki, Helsinki

${ }^{3}$ Faculty of Medicine and HealthTechnology, Tampere University, Tampere, Finland

*Correspondence: To Martin Parnov Reichhardt, martinpreichhardt@gmail.com

Number of tables: 1

Number of figures: 4

Number of words: 4357

This article has been accepted for publication and undergone full peer review but has not been through the copyediting, typesetting, pagination and proofreading process, which may lead to differences between this version and the Version of Record. Please cite this article as doi: $\underline{10.1111 / \text { SJI.12987 }}$

This article is protected by copyright. All rights reserved 


\section{Abstract}

The first months of life represent a crucial time period for an infant. Alongside establishing the early microbiome, the mucosal immunological homeostasis is being developed. Both processes may be perturbed in prematurely born infants. The glycoprotein SALSA plays a role in mucosal inflammation and microbial clearance. It is one of the most abundant molecules on the intestinal mucosal surfaces in early life. SALSA binds to many types of microbes and host defense molecules like IgA, C1q and collectin molecules. We here describe the development in fecal SALSA levels during the first three months of life. During these 90 days the median SALSA level in full-term babies decreased from $1100 \mu \mathrm{g} / \mathrm{ml}$ (range $49-17000 \mu \mathrm{g} / \mathrm{ml}$ ) to $450 \mu \mathrm{g} / \mathrm{ml}$ (range 33 $1000 \mu \mathrm{g} / \mathrm{ml}$ ). Lower levels of SALSA were observed in prematurely born infants in the same time period. Our novel observation thus indicates an impact of prematurity on an important component of the infant intestinal immune system. Changes in SALSA in early life may have an effect on the early establishment of the human microbiome.

\section{Keywords}

Infant, dmbt1, premature, IgA, complement, C1q, intestine, gp340 


\section{Introduction}

The Salivary Scavenger and Agglutinin (SALSA), also known as dmbt1 and gp340 is a large glycoprotein found on the mucosal surfaces of the human body. Previous studies have linked the SALSA molecule to anti-microbial functions, suppression of inflammation, as well as epithelial homeostasis ${ }^{1-3}$. SALSA binds to microbial pathogens and inhibits their colonization on the human surfaces ${ }^{4-6}$. In addition, SALSA interacts with endogenous immune defence molecules, such as IgA, surfactant proteins SP-A, SP-D and complement C1q and MBL ${ }^{7-11}$. SALSA is composed of fourteen conserved scavenger receptor cysteine-rich domains, thirteen of these displaying a ligand binding site ${ }^{12}$. This facilitates the interaction with a large number of ligands. SALSA is thus suggested to mediate a cooperative molecular immune defence against invading microbes, and thereby contribute to the integrity of the mucosal barrier.

It has been estimated that SALSA makes up close to $10 \%$ of the total protein content in the meconium and the saliva of young children $(<3$ years $){ }^{13,14}$. This makes SALSA one of the most abundant proteins on these mucosal surfaces in early life, highlighting an important role at this stage. Upregulation of SALSA expression seems to be a part of the normal response to epithelial inflammation ${ }^{6,15,16}$. Altered expression of SALSA has been linked to a number of inflammatory conditions, including chronic sinusitis, cystic fibrosis, Crohn's disease and ulcerative colitis 6,11,1618 .

Immediately after birth, while establishing the microbiome of the individual, an appropriate and concomitant immune regulation is essential. It is well known that the development of the immune system is affected in prematurely born infants, with several potential complications ensuing ${ }^{19}$. As an example, it has been estimated that up to $30 \%$ of infants born before gestation week 32 will experience at least one instance of clinical or microbiologically confirmed sepsis ${ }^{20}$. Previous studies of SALSA in infants using immunohistochemistry and RNA in situ hybridization identified SALSA expression at the earliest developmental stages of the gastrointestinal system ${ }^{21}$. Furthermore, it was shown that a number of early-life complications associated with strong systemic inflammatory responses, such as necrotizing enterocolitis, volvulus and intestinal perforation, were accompanied by an upregulation of SALSA expression ${ }^{21}$. Combined, these studies indicate the importance of further understanding the local intestinal immune environment 
in the earliest days of life. In particular, we need to focus on the most abundant immune molecules, such as SALSA.

In this study we aimed at quantifying the intestinal levels of SALSA in infants. By measuring concentrations of the SALSA protein in feces within the first 90 days of life, we were able to show a time-course of the development of the SALSA levels. Furthermore, we included in our study a cohort of prematurely born infants. Our analysis shows significantly lower levels of SALSA in prematurely born compared to full-term babies. This suggests a disturbed immune homeostasis in the intestines of prematurely born infants, which may contribute to increased susceptibility to infections or immune-mediated disorders. 


\section{Materials and Methods}

\section{Sample collection}

Fecal samples were collected from two cohorts of babies including both full-term ( 38 weeks +1 days to 42 weeks +2 days, $n=34)$ and prematurely born $(23$ weeks +2 days to 30 weeks +4 days, $\mathrm{n}=38$ ) infants. Study participants were recruited at the Neonatal Intensive Care Unit of Children's Hospital, Helsinki University Hospital between November 2016 and August 2018, and at the Jorvi Hospital, part of the Helsinki University Hospital, Finland, between September 2015 and February 2016. Exclusion criteria for full-term infants were maternal antibiotic use during pregnancy, birth weight $<2500 \mathrm{~g}$ or congenital malformations. The study samples were collected at regular intervals within the first three months of life, frozen and stored at $-20^{\circ} \mathrm{C}$.

\section{Preparation of fecal samples}

Flash-frozen fecal samples were thawed on ice. $125 \mathrm{mg}$ of feces was mixed with $375 \mu \mathrm{PBS}$ and added to a FastPrep tube (2-ml Lysing Matrix D tube, MP Biomedicals, Germany). The tubes were run on the FastPrep-24 ${ }^{\mathrm{TM}}$ (MP Biomedicals, Germany) for 5 x $45 \mathrm{~s}$ at $6.5 \mathrm{~m} / \mathrm{s}$, with cooling on ice between each cycle. The samples were spun at $4^{\circ} \mathrm{C}$, first at $10,000 \mathrm{~g}$ for $5 \mathrm{~min}$ followed by $14,000 \mathrm{~g}$ for $8 \mathrm{~min}$. The supernatants were collected, and the SALSA concentrations were analysed by ELISA.

\section{ELISA}

On a Maxisorp plate (Nunc, Denmark) $100 \mu \mathrm{l}$ standard (with known SALSA concentration) as well as fecal homogenates (dilutions starting at 1:900) were coated $\mathrm{O} / \mathrm{N}$ at $4^{\circ} \mathrm{C}$ in TBS with $1 \mathrm{mM}$ $\mathrm{CaCl}_{2}$ (TBS-Ca). The plates were washed $5 \mathrm{x}$ in TBS-Ca containing $0.05 \%$ Tween 20, and blocked with $3 \%$ milk. The plates were washed $5 \mathrm{x}$ in TBS-Ca/Tween and incubated with monoclonal anti-SALSA antibody (1G4, Novus Biologicals, UK) diluted 1:20,000 in TBS-Ca, 100 $\mu \mathrm{l} /$ well for $1 \mathrm{~h}$ at $37^{\circ} \mathrm{C}$. The plates were washed as before and HRP-conjugated goat anti-mouse antibody (Dako \#P0447, Glostrup, Denmark) was added at a 1:10,000 dilution in TBS-Ca, 100 $\mu \mathrm{l} /$ well for $1 \mathrm{~h}$ at $37^{\circ} \mathrm{C}$. The plate was developed with TMB (1-StepTM Ultra TMB-ELISA, Thermo Scientific, Rockford, IL, USA), $100 \mu \mathrm{l} /$ well. The signal was analyzed by spectrophotometry at $450 \mathrm{~nm}$, and corrected for background at $540 \mathrm{~nm}$. 


\section{Statistics}

Statistical analysis was performed to compare differences between samples in two sample groups by using the 2-tailed unpaired student's t-test.

This article is protected by copyright. All rights reserved 


\section{Results}

Our previous observation of SALSA as the most abundant protein in meconium indicated an important and robust role for this molecule in the infant intestine. We therefore conducted a longitudinal study exploring the SALSA levels in infant feces in the course of the first three months of life. Included in the study were both cohorts of full-term as well as prematurely born infants (see Table 1). Feces samples were collected at regular time intervals starting from birth and extending until day 90 after birth (see Figure 1).

\section{Figure 1}

The SALSA concentrations were measured using a previously described assay (ELISA), based on detection with a specific monoclonal antibody (1G4). An overall trend of decreasing SALSA concentration in the infant feces since birth was observed for both full-term and premature infants. Due to the nature of sampling in this study, including follow-up with healthy infants out of hospital, samples were collected at slightly varying time-points after birth. To further quantify the observed trend of decreasing SALSA levels, samples were therefore divided into four groups; week 1, week 2, weeks 3-4 and weeks 5-12 after birth. SALSA levels within each group were then compared between full-term infants and prematurely born infants (see Figure 2).

Figure 2

The data in Figure 2 demonstrates a clear decrease in SALSA levels over time, in both full-term (n $=34)$ and prematurely born $(\mathrm{n}=38)$ infants. Over the 90-day period the median SALSA level in the full-term babies decreased from $1100 \mu \mathrm{g} / \mathrm{ml}$ (range $49-17000 \mu \mathrm{g} / \mathrm{ml}$ ) to $450 \mu \mathrm{g} / \mathrm{ml}$ (range 33 $-1000 \mu \mathrm{g} / \mathrm{ml}$ ). In the group of prematurely born infants the respective median value decreased from 850 (range $74-7800 \mu \mathrm{g} / \mathrm{ml}$ ) to $70 \mu \mathrm{g} / \mathrm{ml}$ (range $11-1100 \mu \mathrm{g} / \mathrm{ml}$ ) over the same period. In addition, we observed a clear trend of lower SALSA levels in prematurely born infants compared to full-term infants. Interestingly, this difference persists over time and is statistically significant after 15 days $(p<0.004)$, Student's t-test). 
To further analyze the development of SALSA levels after birth, potential associations with gender and delivery mode were analyzed in full-term infants (see Figure 3).

Figure 3

Using the same grouping of samples; week 1, week 2, weeks 3-4 and weeks 5-12 after birth, SALSA levels were compared for female $(n=13)$ and male $(n=21)$ full-term infants (Figure 3A). Over the 90-day period the median SALSA value in the females decreased from 1200 (range 49 $5000 \mu \mathrm{g} / \mathrm{ml}$ ) to $470 \mu \mathrm{g} / \mathrm{ml}$ (range $310-810 \mu \mathrm{g} / \mathrm{ml}$ ), whereas the respective value in males decreased from 900 (range $60-17000 \mu \mathrm{g} / \mathrm{ml}$ ) to $430 \mu \mathrm{g} / \mathrm{ml}$ (range $34-1000 \mu \mathrm{g} / \mathrm{ml}$ ). The SALSA levels were slightly higher in females throughout the measured time period, but the difference was statistically significant only within $15-30$ days after birth $(p<0.03)$.

Next, we compared full-term children born by vaginal delivery $(n=26)$ to children born by Caesarean section $(n=6)$. Only a weak trend of higher SALSA levels following vaginal delivery was observed (Figure 3B). For the full-term children born by Caesarean section samples were not available throughout the entire 90-day period. The comparison was therefore only conducted over the first week of life (days $0-6$ ). The observed difference was not statistically significant.

Jaundice is a complication observed in some infants, often arising immediately after birth and especially in those born prematurely. To investigate a correlation with SALSA levels, we therefore next compared SALSA concentrations in prematurely born infants with $(\mathrm{n}=28)$ or without $(\mathrm{n}=$ 10) jaundice (Figure 4). Here, jaundice was defined as bilirubin levels above $100 \mu \mathrm{mol} / \mathrm{l}$.

\section{Figure 4}

Within the first week of life SALSA levels appeared lower in infants with jaundice (median 460 $\mu \mathrm{g} / \mathrm{ml}$, range $88-4400 \mu \mathrm{g} / \mathrm{ml}$ ) compared to infants without jaundice (median $920 \mu \mathrm{g} / \mathrm{ml}$, range $360-7800 \mu \mathrm{g} / \mathrm{ml}$ ). A similar observation was seen for the second week of life (days 7-14). Neither of these differences were, however, statistically significant. Furthermore, in contrast to the early timepoints, the later period investigated here (15 - 30 days), showed higher SALSA levels in 
infants with jaundice (median $210 \mu \mathrm{g} / \mathrm{ml}$, range $8-1200 \mu \mathrm{g} / \mathrm{ml}$ ) compared to infants without jaundice (median $70 \mu \mathrm{g} / \mathrm{ml}$, range $5-440 \mu \mathrm{g} / \mathrm{ml}$ ).

This article is protected by copyright. All rights reserved 


\section{Discussion}

The SALSA protein has previously been linked to immunological homeostasis at the intestinal mucosal surfaces ${ }^{1-3}$. Based on its very high abundance, the protein seems to play a crucial role during early life ${ }^{13,14}$. In the current study we describe, for the first time, the development of the fecal SALSA levels during the first three months of life. This period is critical for the development of the local immune system and for the establishment of the microbiome. Microbial dysbiosis during this time has been associated with disease development in humans ${ }^{22}$. Over the 90-day period our results show a decrease in fecal SALSA concentrations in healthy full-term infants from 1200 (range $49-17000 \mu \mathrm{g} / \mathrm{ml}$ ) in the first week of life to $450 \mu \mathrm{g} / \mathrm{ml}$ (range $33-1000 \mu \mathrm{g} / \mathrm{ml}$ ) at 12 weeks. In addition, we found significantly lower levels of SALSA in feces from prematurely born infants. This suggests that SALSA production is related to the under-developed immune status of prematurely born infants.

Samples for individual infants in our cohorts were not taken at exactly the same time points postpartum. As the trend of lower SALSA levels over time is evident for all infants, the specific sampling time could potentially impact our analysis, and skew the comparison of full-term and prematurely born infants within each of the four sampling periods (week 1, week 2, weeks 3-4 and weeks 5-12). However, all full-term samples were taken at the end of a given sample period (e.g. in week 12, for the group of 5-12 weeks). Thus, any effect from time-differences of sampling would be expected to yield a lower level of SALSA in full-term compared to prematurely born infants. We observed the opposite. Indeed, with the sampling-time in mind, we may suggest that the observed differences between full-term and prematurely born infants in our study are even bigger in reality.

In full-term infants slightly higher SALSA concentrations were observed in female than male infants throughout the investigated time period. This difference was only statistically significant from 15-30 days postpartum. No gender differences in mucosal SALSA levels have previously been described, neither in infants nor adults. Although the timing of sampling for each gendergroup was comparable, there was an over-representation of male $(n=21)$ vs female $(n=13)$ infants, which may affect the analysis. However, gender differences are commonly observed for both innate and adaptive components of the immune system ${ }^{23}$. Indeed, sexually dimorphic gene 
expression patterns have been demonstrated in pre-pubescent mice in the intestinal compartment ${ }^{24}$. To fully understand the relevance of this observation, additional studies will be required.

Our data did not demonstrate altered levels of SALSA in infants born following Caesarean section, and neither did our data demonstrate a convincing alteration in SALSA expression in infants with jaundice. Altered expression of SALSA in the epithelium of the bile ducts has previously been observed in hepatic pathologies in adults ${ }^{25}$. However, in this case increased expression was correlated to pathology, such as hepatolithiasis, which is expected to induce an inflammatory reaction in the local epithelium. In contrast, a slight trend of lower SALSA levels was seen in infants with jaundice during the first two weeks of life, the timepoint of active jaundice. However, this difference was not statistically significant.

Although our studies identify a novel immunological alteration in prematurely born infants, the interpretation of its impact comes with certain limitations. The measurement of feces content is not equivalent to an investigation of the actual local inflammatory environment in the gut. First of all, the expression of SALSA varies throughout the gut ${ }^{26-29}$. Secondly, during the passing of the stool there may be a disproportionately high or low concentration or dilution of the protein, which is impossible to estimate. The measured concentrations of SALSA in the feces are therefore only an approximation of the exact situation in the gut. However, without the use of invasive techniques to analyze the infants, our approach offers a relevant and comparable method to investigate general levels of this protein in the intestinal environment.

Increasing evidence has shown that the immune system in the newborns is not just an immature version of the adult defence. Rather, it is quantitatively and qualitatively different ${ }^{30}$. In prematurely born infants, this essential immunological development is altered leading to a number of immediate consequences 19,31. These include increased risk of necrotizing enterocolitis and other neonatal infections resulting in high morbidity and mortality rates ${ }^{32}$. However, the consequences of preterm birth may reach even further, leading to susceptibility to immune-derived diseases later in life, such as asthma and allergies 22,33,34. Although certain longitudinal studies suggest that early immunological differences observed in children born prematurely may even out over time ${ }^{35}$, studies on immune regulation in early life remain of paramount importance. Intestinal SALSA levels are increased in response to microbial infections and inflammation as part of a 
normal developed immune response. The variation between full term and preterm infants described in this study indicates that the ability to direct an appropriate innate immune response to e.g. microbial challenges is different in the two groups. The current study thus shows that SALSA is one of the many components in the innate immune defence that is altered with prematurity. Links to neonatal complications, such as necrotizing colitis, have already been described for SALSA $^{21}$. The importance of this molecule in early life, indicated by its abundance and impact on the colonizing microbiota, warrants further studies into the outcome of altered SALSA levels in the local mucosal environment in the developing infants. 


\section{Ethics statement}

The guardians of the term babies signed an informed consent and participated in a study focusing on early life microbiome and related factors, approved by the ethical committee of The Hospital District of Helsinki and Uusimaa (370/13/03/03/2014) and (126/13/03/03/2016)

\section{Author Contributions}

MPR: Designed the research, performed the research, analysed the data, and wrote the paper.

MM: Performed the research, analysed the data.

SA: Collected samples, analysed the data.

KLK: Collected samples, analysed the data.

SM: Designed the research, analysed the data, and wrote the paper.

\section{Acknowledgements}

The authors thank all infants enrolled in the study, as well as their families. RN Anne Nikkonen is thanked for help in gathering patient data. Financial support was granted from the Pediatic Research Foundation (KLK), the Sigrid Jusélius Foundation, the Academy of Finland (292393) and Helsinki University Central Hospital (TYH2018313, TYH2019311) grants (SM).

\section{Conflict of Interest Statement}

The authors proclaim no conflict of interests. 


\section{References}

1. Madsen J, Mollenhauer J, Holmskov U. Review: Gp-340/DMBT1 in mucosal innate immunity. Innate Immun 2010;16:160-7.

2. Reichhardt MP, Meri S. SALSA: A Regulator of the Early Steps of Complement Activation on Mucosal Surfaces. Front Immunol 2016;7:85.

3. Reichhardt MP, Holmskov U, Meri S. SALSA-A dance on a slippery floor with changing partners. Mol Immunol 2017;89:100-10.

4. Hartshorn KL, White MR, Mogues T, Ligtenberg T, Crouch E, Holmskov U. Lung and salivary scavenger receptor glycoprotein-340 contribute to the host defense against influenza A viruses. Am J Physiol Lung Cell Mol Physiol 2003;285:L1066-76.

5. Loimaranta V, Jakubovics NS, Hytonen J, Finne J, Jenkinson HF, Stromberg N. Fluid- or surface-phase human salivary scavenger protein gp340 exposes different bacterial recognition properties. Infect Immun 2005;73:2245-52.

6. Rosenstiel P, Sina C, End C, et al. Regulation of DMBT1 via NOD2 and TLR4 in intestinal epithelial cells modulates bacterial recognition and invasion. J Immunol 2007; 178:8203-11.

7. Rundegren J, Arnold RR. Differentiation and interaction of secretory immunoglobulin A and a calcium-dependent parotid agglutinin for several bacterial strains. Infect Immun 1987;55:288-92.

8. Boackle RJ, Connor MH, Vesely J. High molecular weight non-immunoglobulin salivary agglutinins (NIA) bind C1Q globular heads and have the potential to activate the first complement component. Mol Immunol 1993;30:309-19.

9. Holmskov U, Lawson P, Teisner B, et al. Isolation and characterization of a new member of the scavenger receptor superfamily, glycoprotein-340 (gp-340), as a lung surfactant protein-D binding molecule. J Biol Chem 1997;272:13743-9.

10. Reichhardt MP, Loimaranta V, Thiel S, Finne J, Meri S, Jarva H. The salivary scavenger and agglutinin binds MBL and regulates the lectin pathway of complement in solution and on surfaces. Front Immunol 2012;3:205.

11. Madsen J, Sorensen GL, Nielsen O, et al. A variant form of the human deleted in malignant brain tumor 1 (DMBT1) gene shows increased expression in inflammatory 
bowel diseases and interacts with dimeric trefoil factor 3 (TFF3). PLoS One 2013;8:e64441.

12. Reichhardt MP, Loimaranta V, Lea SM, Johnson S. Structures of SALSA/DMBT1 SRCR domains reveal the conserved ligand-binding mechanism of the ancient SRCR fold. Life Sci Alliance 2020;3:10.26508/1sa.201900502. Print 2020 Apr.

13. Sonesson M, Ericson D, Kinnby B, Wickstrom C. Glycoprotein 340 and sialic acid in minor-gland and whole saliva of children, adolescents, and adults. Eur J Oral Sci 2011;119:435-40.

14. Reichhardt MP, Jarva H, de Been M, et al. The Salivary Scavenger and Agglutinin in Early Life: Diverse Roles in Amniotic Fluid and in the Infant Intestine. J Immunol 2014.

15. Kang W, Nielsen O, Fenger C, et al. The scavenger receptor, cysteine-rich domaincontaining molecule gp-340 is differentially regulated in epithelial cell lines by phorbol ester. Clin Exp Immunol 2002;130:449-58.

16. Renner M, Bergmann G, Krebs I, et al. DMBT1 confers mucosal protection in vivo and a deletion variant is associated with Crohn's disease. Gastroenterology 2007;133:1499-509.

17. Kim TH, Lee SH, Lee HM, et al. Increased expression of glycoprotein 340 in the ethmoid sinus mucosa of patients with chronic sinusitis. Arch Otolaryngol Head Neck Surg 2007;133:1111-4.

18. Hamm CM, Reimers MA, McCullough CK, et al. NOD2 status and human ileal gene expression. Inflamm Bowel Dis 2010;16:1649-57.

19. Kamdar S, Hutchinson R, Laing A, et al. Perinatal inflammation influences but does not arrest rapid immune development in preterm babies. Nat Commun 2020;11:1284,02014923-8.

20. ELFIN trial investigators group. Enteral lactoferrin supplementation for very preterm infants: a randomised placebo-controlled trial. Lancet 2019;393:423-33.

21. Muller H, Renner M, Helmke BM, Mollenhauer J, Felderhoff-Muser U. Elevated DMBT1 levels in neonatal gastrointestinal diseases. Histochem Cell Biol 2016;145:227-37.

22. Arrieta MC, Stiemsma LT, Dimitriu PA, et al. Early infancy microbial and metabolic alterations affect risk of childhood asthma. Sci Trans1 Med 2015;7:307ra152.

23. Klein SL, Flanagan KL. Sex differences in immune responses. Nat Rev Immunol 2016;16:626-38. 
24. Steegenga WT, Mischke M, Lute C, et al. Sexually dimorphic characteristics of the small intestine and colon of prepubescent C57BL/6 mice. Biol Sex Differ 2014;5:11,014-0011-9. eCollection 2014.

25. Sasaki M, Huang SF, Chen MF, et al. Expression of deleted in malignant brain tumor-1 (DMBT1) molecule in biliary epithelium is augmented in hepatolithiasis: possible participation in lithogenesis. Dig Dis Sci 2003;48:1234-40.

26. Mollenhauer J, Wiemann S, Scheurlen W, et al. DMBT1, a new member of the SRCR superfamily, on chromosome 10q25.3-26.1 is deleted in malignant brain tumours. Nat Genet 1997; 17:32-9.

27. Holmskov U, Mollenhauer J, Madsen J, et al. Cloning of gp-340, a putative opsonin receptor for lung surfactant protein D. Proc Natl Acad Sci U S A 1999;96:10794-9.

28. Mollenhauer J, Herbertz S, Holmskov U, et al. DMBT1 encodes a protein involved in the immune defense and in epithelial differentiation and is highly unstable in cancer. Cancer Res 2000;60:1704-10.

29. Mollenhauer J, Herbertz S, Helmke B, et al. Deleted in Malignant Brain Tumors 1 is a versatile mucin-like molecule likely to play a differential role in digestive tract cancer. Cancer Res 2001;61:8880-6.

30. Gibbons D, Fleming P, Virasami A, et al. Interleukin-8 (CXCL8) production is a signatory $\mathrm{T}$ cell effector function of human newborn infants. Nat Med 2014;20:1206-10.

31. Gibbons DL, Haque SF, Silberzahn T, et al. Neonates harbour highly active gammadelta T cells with selective impairments in preterm infants. Eur J Immunol 2009;39:1794-806.

32. Puiman PJ, Burger-Van Paassen N, Schaart MW, et al. Paneth cell hyperplasia and metaplasia in necrotizing enterocolitis. Pediatr Res 2011;69:217-23.

33. Been JV, Lugtenberg MJ, Smets E, et al. Preterm birth and childhood wheezing disorders: a systematic review and meta-analysis. PLoS Med 2014;11:e1001596.

34. Mitselou N, Hallberg J, Stephansson O, Almqvist C, Melen E, Ludvigsson JF. Cesarean delivery, preterm birth, and risk of food allergy: Nationwide Swedish cohort study of more than 1 million children. J Allergy Clin Immunol 2018;142:1510,1514.e2.

35. Olin A, Henckel E, Chen Y, et al. Stereotypic Immune System Development in Newborn Children. Cell 2018;174:1277,1292.e14. 


\section{Tables}

Table 1: Details of infants in premature and full-term cohorts. Gestational age at birth is given as weeks + days $(w+d)$.

\begin{tabular}{|l|c|l|l|l|l|l|c|}
\hline Cohort & Infants & $\begin{array}{l}\text { Number } \\
\text { of fecal } \\
\text { samples }\end{array}$ & $\begin{array}{l}\text { Gestational } \\
\text { age }(\mathrm{w}+\mathrm{d}): \\
\text { median } \\
(\text { range })\end{array}$ & $\begin{array}{l}\text { Birthweight } \\
(\mathrm{g}) \text { : median } \\
(\text { range })\end{array}$ & $\begin{array}{l}\text { Female } \\
/ \text { Male }\end{array}$ & $\begin{array}{l}\text { Caesarean } \\
\text { section / } \\
\text { Vaginal } \\
\text { delivery }\end{array}$ & Jaundice \\
\hline Premature & 38 & 115 & $\begin{array}{c}27+3(23+ \\
2-30+4)\end{array}$ & $\begin{array}{c}1030(510- \\
1630)\end{array}$ & $18 / 20$ & $27 / 11$ & 28 \\
\hline Full-term & 34 & 105 & $\begin{array}{c}40(38+1- \\
42+2)\end{array}$ & $\begin{array}{c}3566(3004 \\
-3820)\end{array}$ & $13 / 21$ & $8 / 26$ & 2 \\
\hline
\end{tabular}




\section{Figure legends}

\section{Figure 1. SALSA levels over time.}

Fecal samples were collected at varying time points during the first 90 days of life starting from the first stool. There were 72 infants included. The samples were suspended to a fixed volume, and the SALSA concentrations were determined by ELISA. Black spheres denote samples taken from children born after a full-term pregnancy. Red triangles denote samples taken from children born prematurely (before gestation week 32).

\section{Figure 2. Differences in SALSA levels between full-term and prematurely born infants.}

Fecal samples were divided into four groups based on the timing of collection; 0-6, 7-14, 15-30 and 31-90 days postpartum. SALSA levels were averaged within each group, and used for comparison between full-term infants (open boxes) and prematurely born infants (dotted boxes). Displayed for each group are median and boxed interquartiles. The full range of sampling is represented by whiskers. Number of samples in each group is indicated above each bar $(\mathrm{N})$. An unpaired, 2-tailed Student's t-test was used to compare differences between sample groups. ${ }^{*} \mathrm{p}<$ 0.05 .

\section{Figure 3. The effect of gender and birth mode on SALSA levels.}

SALSA levels in full-term infants were analyzed for differences relative to gender or delivery mode. (A) Female vs male infants. Fecal samples were divided into four groups based on the timing of collection; 0-6, 7-14, 15-30 and 31-90 days postpartum. Displayed are median and interquartile ranges for female infants $(n=13$, open boxes $)$ and male infants $(n=21$, dotted boxes) infants in each group. The full range of sampling is represented by whiskers. An unpaired, 2-tailed Student's t-test was used to compare differences between sample groups. ${ }^{*} p<0.03$. (B) Infants born by vaginal delivery $(n=26)$ were compared to infants born by Caesarean section $(n=8)$. Fecal samples were collected within the first week of life (days $0-6$ ), and the SALSA levels were determined. Displayed are individual samples, median and interquartile ranges represented by whiskers. No statistically significant difference was observed.

Figure 4. SALSA levels in prematurely born infants with or without jaundice. 
Fecal samples collected from prematurely born infants were divided into four groups based on the timing of collection; 0-6, 7-14, 15-30 and 31-90 days postpartum Their SALSA levels were compared between infants with jaundice $(n=28)$ and infants without $(n=10)$. Displayed for each group is median and boxed interquartiles. The full range of sampling is represented by whiskers. An unpaired Student's t-test ( 2 tails) was used to compare differences between sample groups, ${ }^{*} p$ $<0.02$. 


\section{Figure 1}

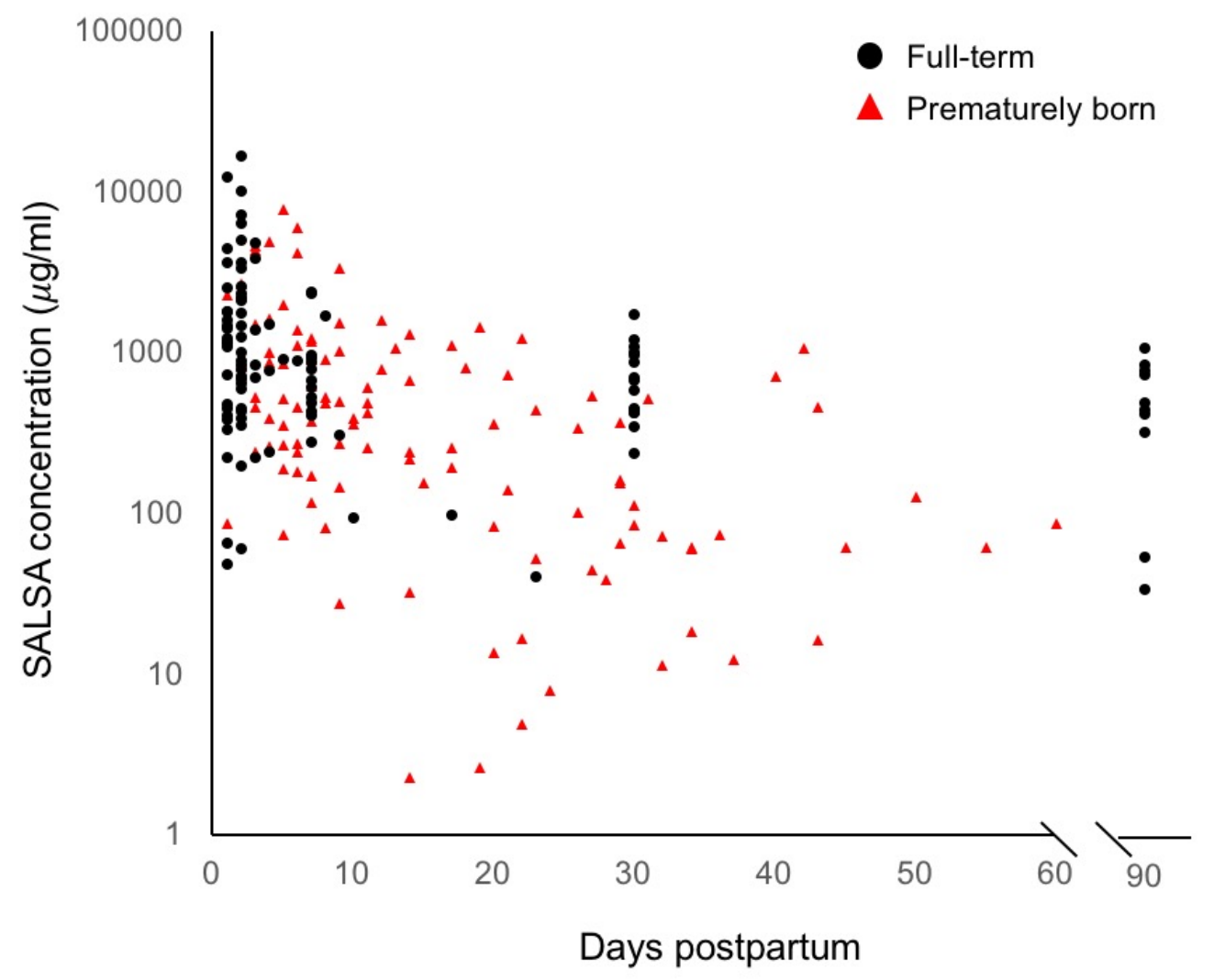

sji_12987_f1.jpg

This article is protected by copyright. All rights reserved 
Figure 2

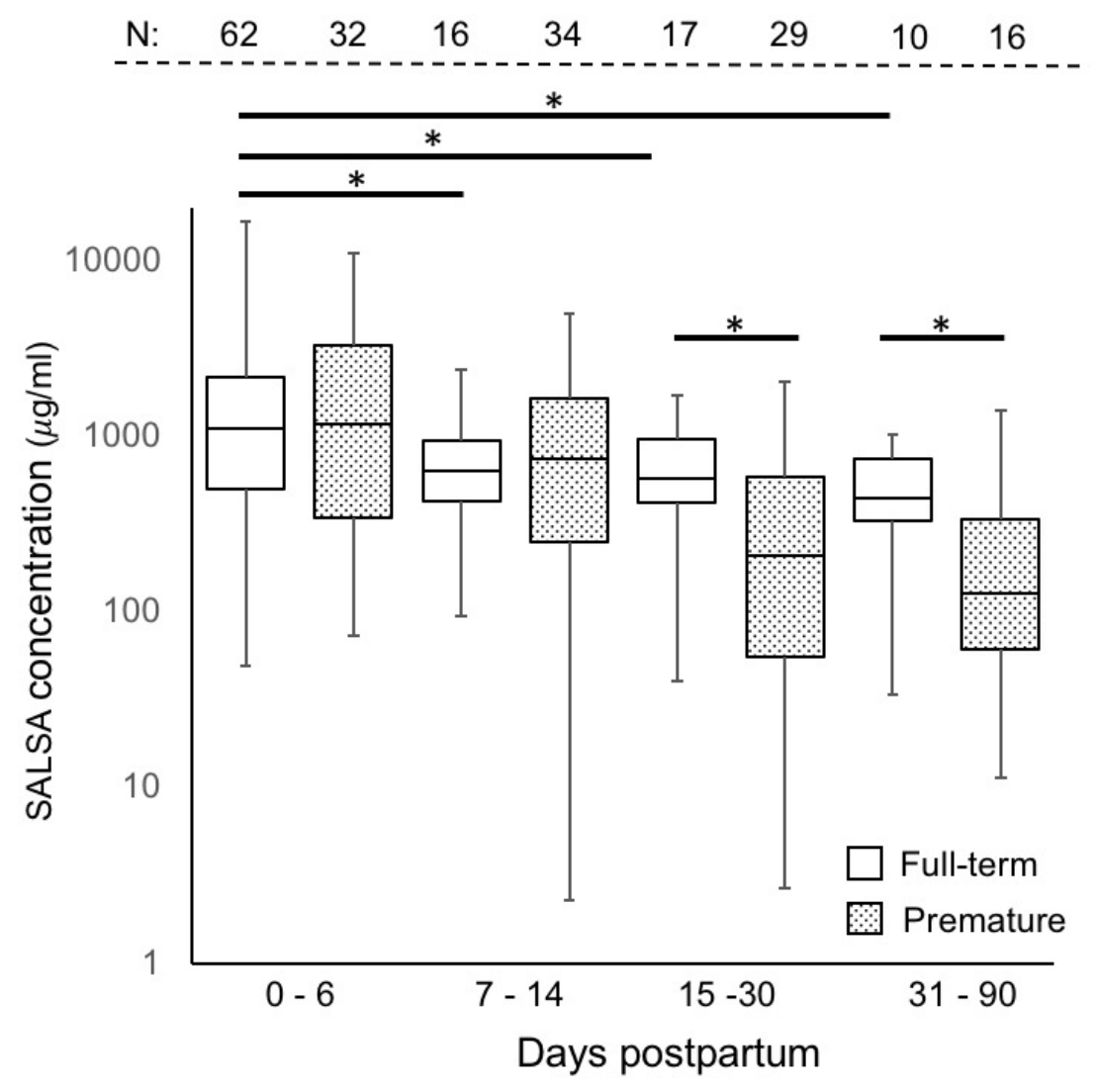

sji_12987_f2.jpg

This article is protected by copyright. All rights reserved 
Figure 3

A)

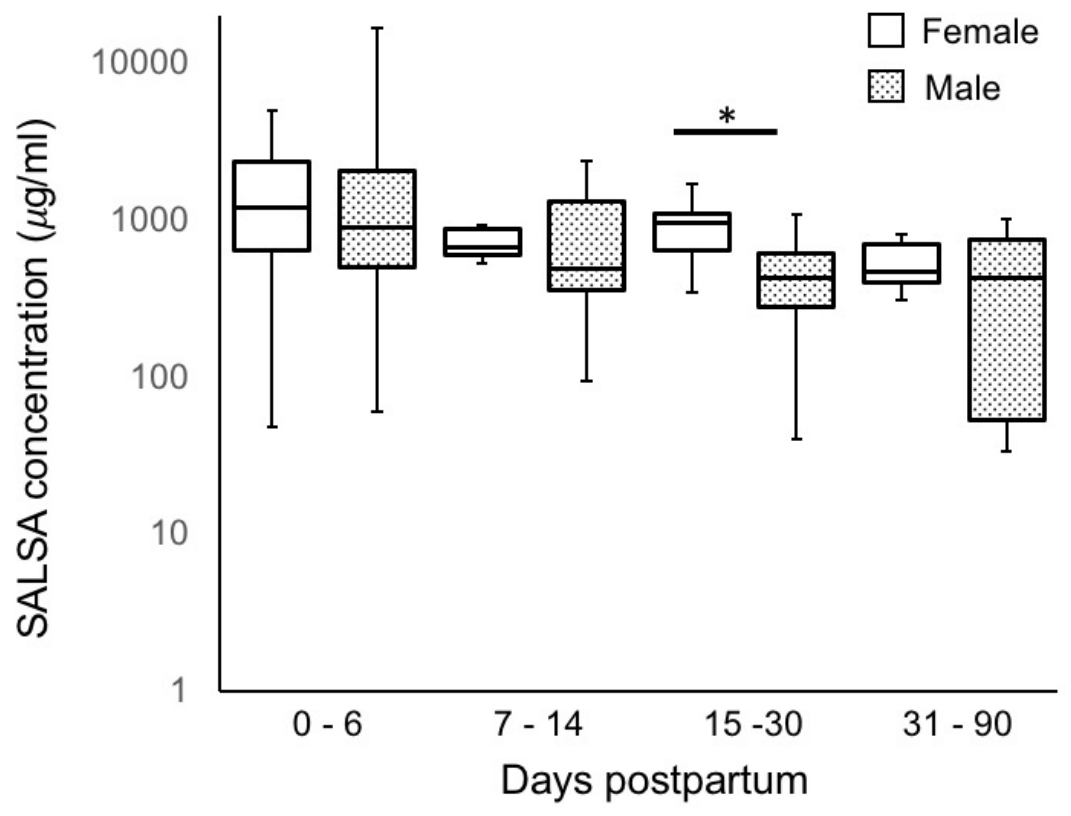

B)

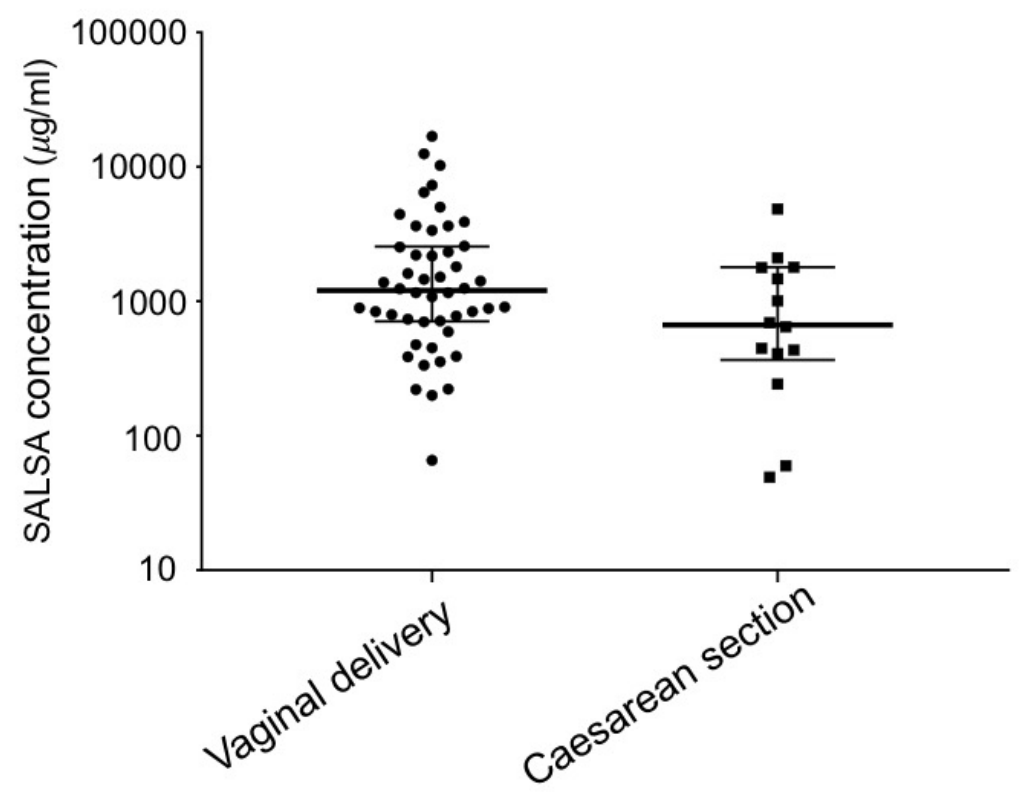

sji_12987_f3.jpg

This article is protected by copyright. All rights reserved 
Figure 4

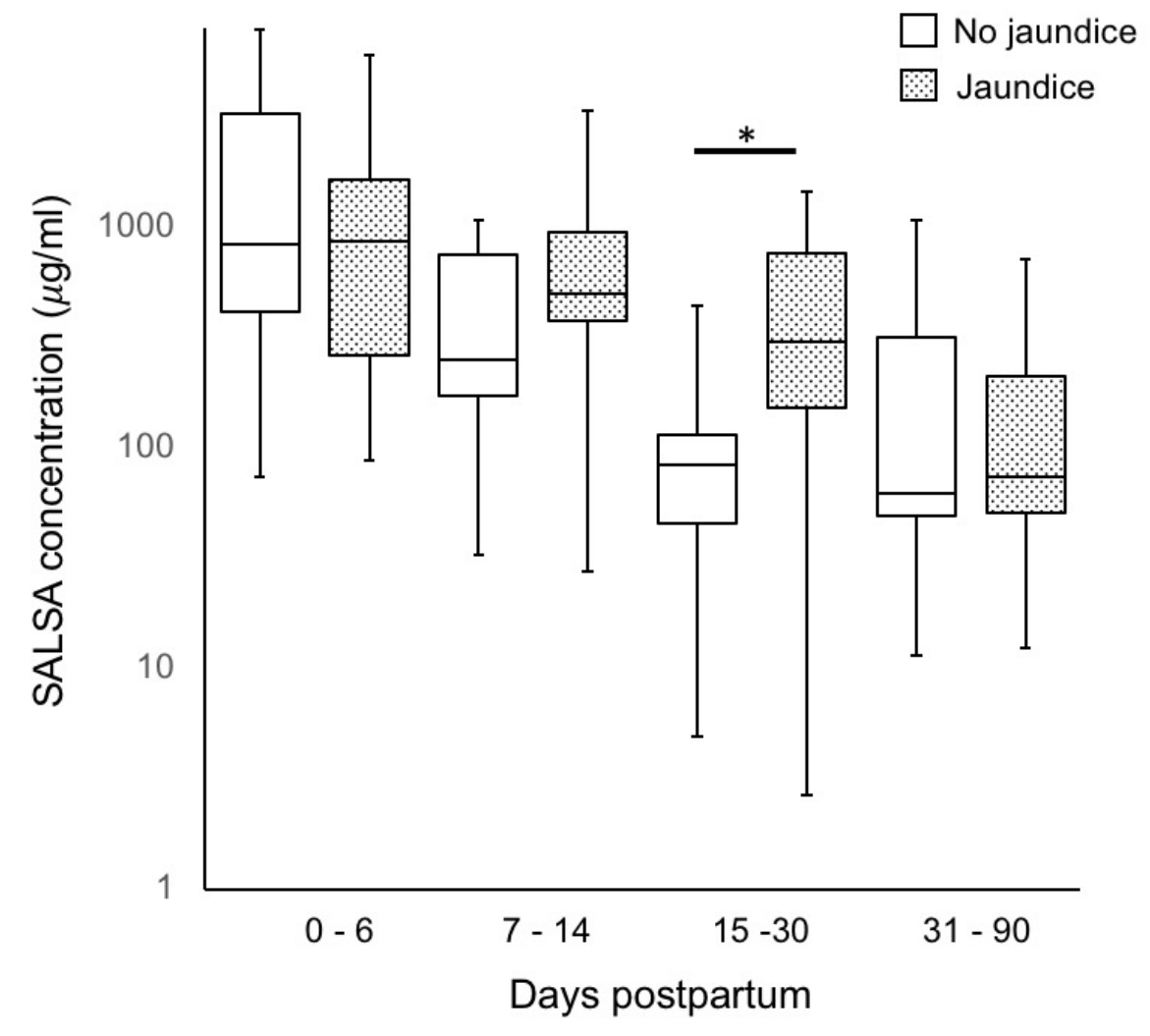

sji_12987_f4.jpg

This article is protected by copyright. All rights reserved 